\title{
MATHEMATICAL MODEL OF THE FLIGHT OF AMMUNITION FIRED FROM AIRPLANE AND ITS ZONE OF DEFEAT AFTER BLASTING
}

\author{
Georgi Evt. Georgiev*, Valentin Djambov and Sasho Popov \\ Institute of Metal Science, Equipment and Technologies \\ with Hydro-and Aerodynamics Centre "Acad. A. Balevski", \\ Bulgarian Academy of Sciences, \\ 67, Shipchenski Prohod Blvd, 1574 Sofia, Bulgaria, \\ e-mails: g.georgiev@ims.bas.bg; valentin@ims.bas.bg; s.popov@ims.bas.bg
}

\begin{abstract}
A mathematical model solving the task of ballistics for freely falling body in the Earth's atmosphere is presented. It is based on the laws of Newtonian mechanics, taking into account all the major factors affecting the flight path of the body. The influence of the changing density of Earth's atmosphere in height, the impact of side wind and frontal and lateral resistance of the body during the flight are reported. In the case when the body is ammunition the defeat zone is obtained and visualized. Based on the developed model suitable PC software is created and presented.

Keywords: ballistics, mathematical modelling, aerodynamics, defeat zones, ammunition effectiveness.
\end{abstract}

\section{INTRODUCTION}

The ballistics is almost as old mechanics branch as the basic equations of classical mechanics created by Sir Isaac Newton [1]. It is widely used over the centuries starting with the ancient catapults for the capture of fortresses and coming to its modern applications in aviation, artillery, directing aircraft ammunition [2], space flight, and many other activities.

This paper aims to create an adequate and easy to use software product that can be applied for solving the problem of ballistics taking into account almost all factors that influence on the law of motion of freely falling body in the Earth's atmosphere. An algorithm and a software visualization of the areas of damage have been created on the basis of the results of ballistics.

\footnotetext{
${ }^{*}$ Corresponding author.

DOI: 10.7546/EngSci.LVI.19.03.02
}

(c) Инженерни науки, год. LVI, 2019, № 3 


\section{MATHEMATICAL MODEL}

Newton's second law of motion of a body with mass $m$ can be written in the following form [1]:

$$
m \ddot{\overrightarrow{\mathbf{r}}}(t)=\vec{G}+\vec{T}+\vec{\Omega},
$$

where $\overrightarrow{\mathbf{r}}(t)$ is the radius-vector to a point of trajectory; $\vec{G}$ - force of gravity; $\vec{T}$ - force of air drag; $\vec{\Omega}$ - side wind force applied on the body.

The initial conditions for a body thrown at an angle $\theta$ to the horizon from height $H_{0}$ have the following form:

$$
\dot{\overrightarrow{\mathbf{r}}}(0)=\vec{v}(0)=\vec{v}_{0}, \quad \overrightarrow{\mathbf{r}}(0)=\left(0,0, H_{0}\right),
$$

where $\vec{v}_{0}$ is the initial velocity of the body.

\subsection{Influence of the air drag without taking into account the side wind}

Considering fall velocity below the sound barrier the norm of aerodynamic drag force $\vec{T}$ (Fig. 1) can be written as follows:

$$
|\vec{T}|=T=\chi \rho S_{b} v^{2}=k_{a} v^{2},
$$

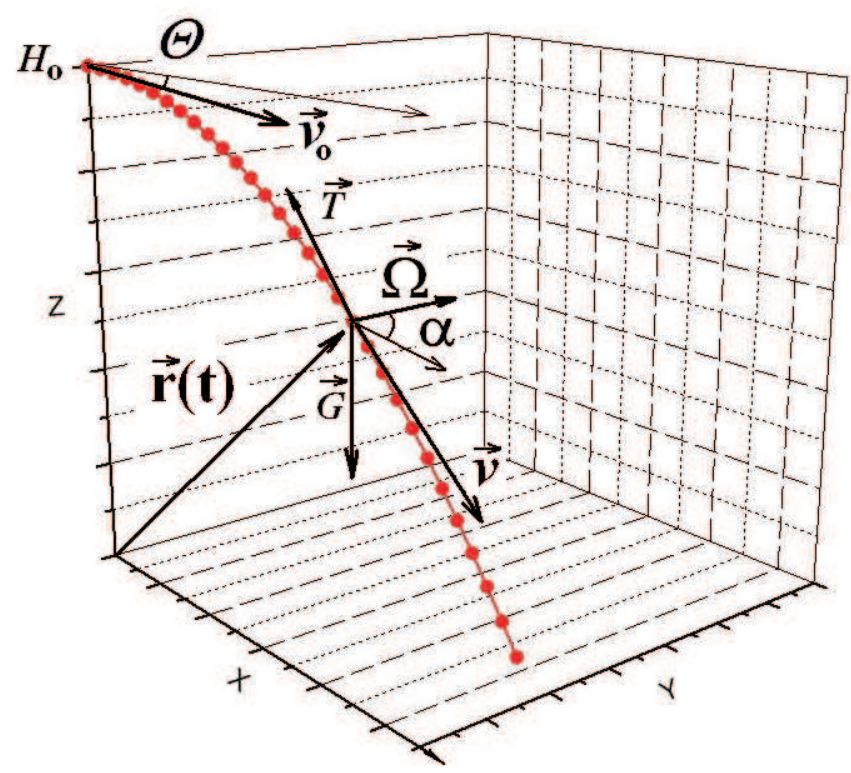

Fig. 1. Scheme of the notations

(c) Инженерни науки, год. LVI, 2019, № 3

15

(c) Engineering Sciences, LVI, 2019, No. 3 
where $k_{a}=\chi \rho S_{b}$ and $\chi$ is the drag coefficient; $\rho$ - air density; $S_{b}$ - cross-section of the body.

Since the direction of $\vec{T}$ is opposite to the direction of the velocity $\vec{v}$, it follows that:

$$
\vec{T}=-k_{a} v^{2} \frac{\vec{v}}{v}=-k_{a} v \vec{v} .
$$

Taking into account the lack of side wind $(\vec{\Omega}=\overrightarrow{0})$, we rewrite (1) by components:

$$
\mid \begin{aligned}
& m \ddot{x}=-k_{a} v \dot{x} \\
& m \ddot{y}=0 \\
& m \ddot{z}=-k_{a} v \dot{z}-m g
\end{aligned}, \quad v=\sqrt{\dot{x}^{2}+\dot{y}^{2}+\dot{z}^{2}},
$$

at the following initial conditions:

$$
\mid \begin{array}{l|l}
v_{x}(0)=\dot{x}(0)=v_{o} \cos \theta & x(0)=0 \\
v_{y}(0)=\dot{y}(0)=0 & y(0)=0 \\
v_{z}(0)=\dot{z}(0)=v_{o} \sin \theta & z(0)=H_{o}
\end{array} .
$$

Since $y(t)=0$ at these conditions, then (5) acquires the form:

$$
\mid \begin{aligned}
& \dot{v}_{x}+a v v_{x}=0 \\
& \dot{v}_{z}+a v v_{z}+g=0
\end{aligned}, \quad v=\sqrt{\dot{x}^{2}+\dot{z}^{2}}
$$

where

$$
a=k_{a} / m
$$

\subsection{Influence of the side wind}

We assume that $z$-component of the velocity $\vec{w}$ of the side wind is equal to zero, i.e. $w_{z}=0$. Further we follow the notations from Fig. 1. The side wind force acting on the body is expressed by the following formula:

$$
\vec{\Omega}=\chi \rho S_{p} w \vec{w}=k_{s} w \vec{w},
$$

where $k_{s}=\chi \rho S_{p}$ and $S_{p}$ is the area of projection of the body in a perpendicular to $\vec{w}$ plane. The angle between $\vec{\Omega}$ and $\mathrm{X}$ axis is denoted as $\alpha$ (Fig. 1). This angle together with $w$ is a part of the initial data for this task. Other quantities have the values given in section above.

Then (1) written by components acquires the form:

$$
\mid \begin{aligned}
& m \dot{v}_{x}+k_{a} v v_{x}-k_{s} w^{2} \cos \alpha=0 \\
& m \dot{v}_{y}+k_{a} v v_{y}-k_{s} w^{2} \sin \alpha=0 \\
& m \dot{v}_{z}+k_{a} v v_{z}+m g=0
\end{aligned}
$$

(c) Инженерни науки, год. LVI, 2019, № 316

(C) Engineering Sciences, LVI, 2019, No. 3 
after substitution

$$
\mid \begin{aligned}
& \dot{v}_{x}+a v v_{x}-b w^{2} \cos \alpha=0 \\
& \dot{v}_{y}+a v v_{y}-b w^{2} \sin \alpha=0 \\
& \dot{v}_{z}+a v v_{z}+g=0
\end{aligned}
$$

$$
b=k_{s} / m
$$

and taking into account (8).

The initial conditions are the same as those in (6).

\subsection{Influence of the flight altitude}

Let us note that $k_{a}$ and $k_{s}$ are not constants. They are functions of the density $\rho$ of the Earth's atmosphere. The density, on its part, is a function of both the height $z(t)$ and the temperature $K$ at this height.

This relationship is not permanent, but for the purposes of aeronautics a standard model of the Earth's atmosphere is adopted, obtained by averaging during the long time $[3,4]$. According to this model used by NASA the mentioned above dependencies are presented in Fig. 2. A good analytical approximation of the pressure $p$ is expressed by the formula [4]:

$$
p(z, K)=p_{a} 10^{-\frac{z}{C[1+\beta K(z / 2)]}},
$$

where $C=18474 ; \beta$ is the coefficient of linear temperature air expansion (= 0.00367); $K$ - air temperature at the corresponding height; $p_{a}$ - atmospheric air pressure at sea level in temperate latitudes; $p$ - atmospheric pressure at height $z$.

On the other hand the equation of ideal gas leads to the relation:

$$
\frac{\rho}{\rho_{a}}=\frac{p K_{a}}{p_{a} K}
$$

where $K_{a}$ is the atmosphere temperature at sea level, and therefore we can write down

$$
\rho=\frac{\rho_{a} K_{a}}{K} 10^{-\frac{z}{C[1+\beta K(z / 2)]}} .
$$

This dependence is put into equations (8) and (12) and therefore in the ballistics equations (11) too. Solving the task and creating the algorithm we have taken into account this dependence. Equations (11) are solved at the non-linear condition (15) and initial conditions in the form:

$$
\mid \begin{aligned}
& v_{x}(0)=v_{o} \cos \theta \\
& v_{y}(0)=0 \\
& v_{z}(0)=v_{o} \sin \theta
\end{aligned} .
$$

(c) Инженерни науки, год. LVI, 2019, № $3 \quad 17$

(C) Engineering Sciences, LVI, 2019, No. 3 


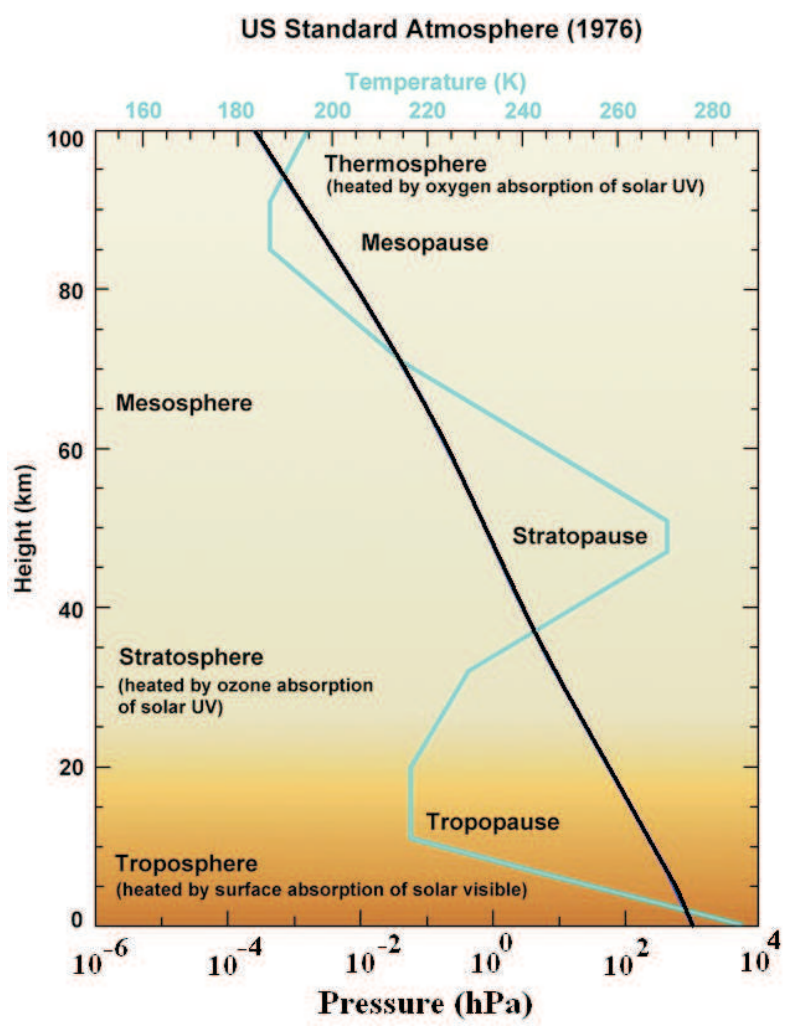

Fig. 2. Temperature dependence on the height in Earth's atmosphere

The solution is realized by a standard program for ordinary differential equations.

Then the obtained velocity is integrated with the following initial conditions:

$$
\mid \begin{aligned}
& x(0)=0 \\
& y(0)=0 \\
& z(0)=H_{0}
\end{aligned} .
$$

In this way we obtain the body law of motion:

$$
\vec{r}(t)=[x(t), y(t), z(t)],
$$

of course numerically because of strong non-linearity of the equations.

(c) Инженерни науки, год. LVI, 2019, № 3

18

(C) Engineering Sciences, LVI, 2019, No. 3 


\subsection{Software realization of the model}

The algorithmic presentation of the model is realized by a version of "Visual FORTRAN" and its standard programs for non-linear ordinary differential equations. The solution visualization is realized on the base of "Delphy". A program that works in interactive mode has been prepared.

An appropriately shaped window allows choosing the type of the body from a preliminary prepared data base. The parameters concerning the ballistics are written in the information fields. Then the input parameters (Fig. 3) are introduced on 3D graphics of the trajectory and the obtained results are displayed on the same graphics in appropriately situated fields (Fig. 3) at the next program step.

The following parameters are obtained as a result:

$\vec{v}_{E}$ - velocity in the final point;

$\phi \quad$ - angle between $\vec{v}_{E}$ and its $z$ component;

$\Psi$ - angle between projection of $\vec{v}_{E}$ in $X Y$ plane and $X$ axis;

$X_{E}-x$-coordinate of the last point of the flay;

$Y_{E}-y$-coordinate of the last point of the flay;

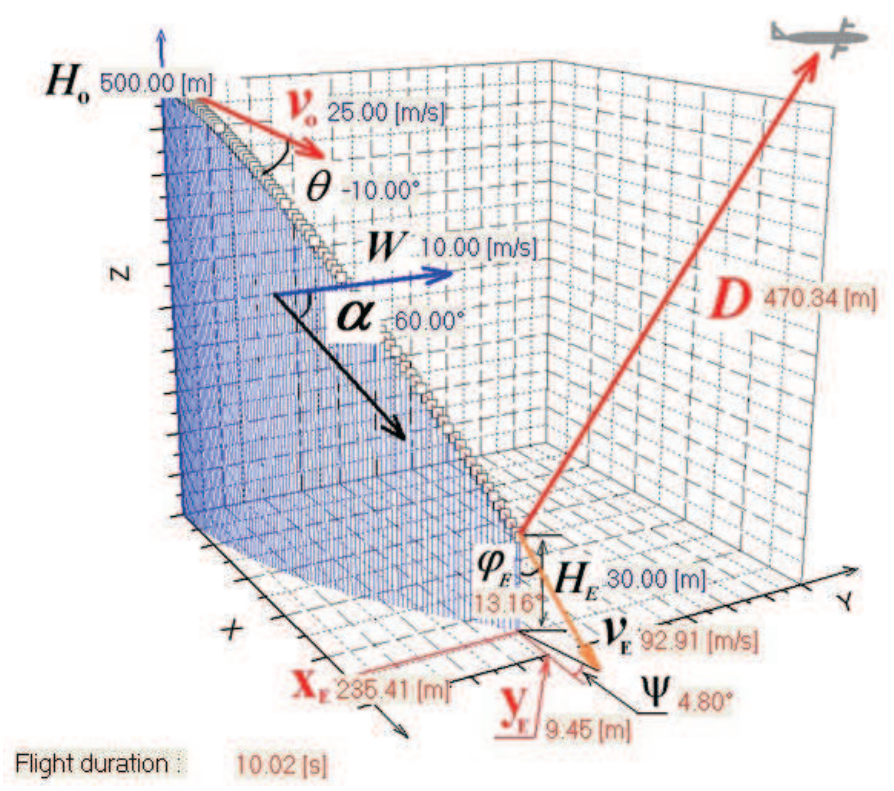

Fig. 3. Initial data and obtained parameters as a result

(c) Инженерни науки, год. LVI, 2019, № 3

19

(C) Engineering Sciences, LVI, 2019, No. 3 


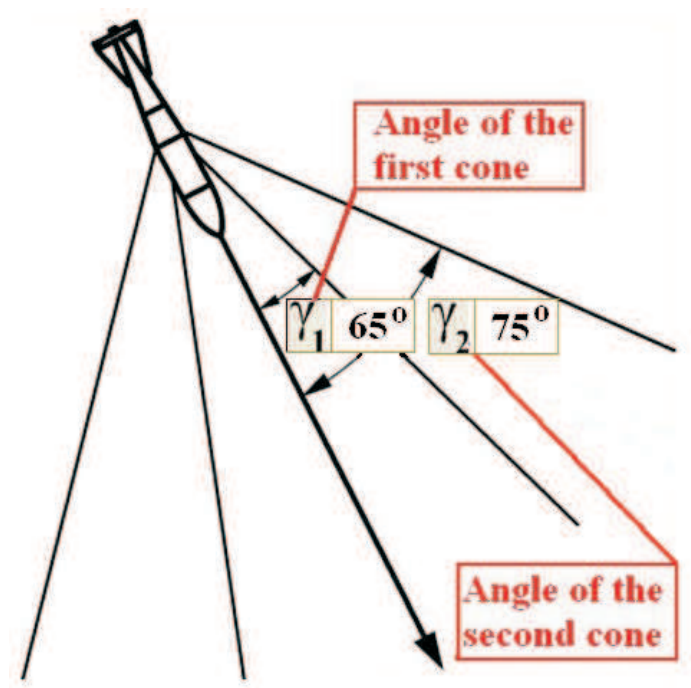

(a)

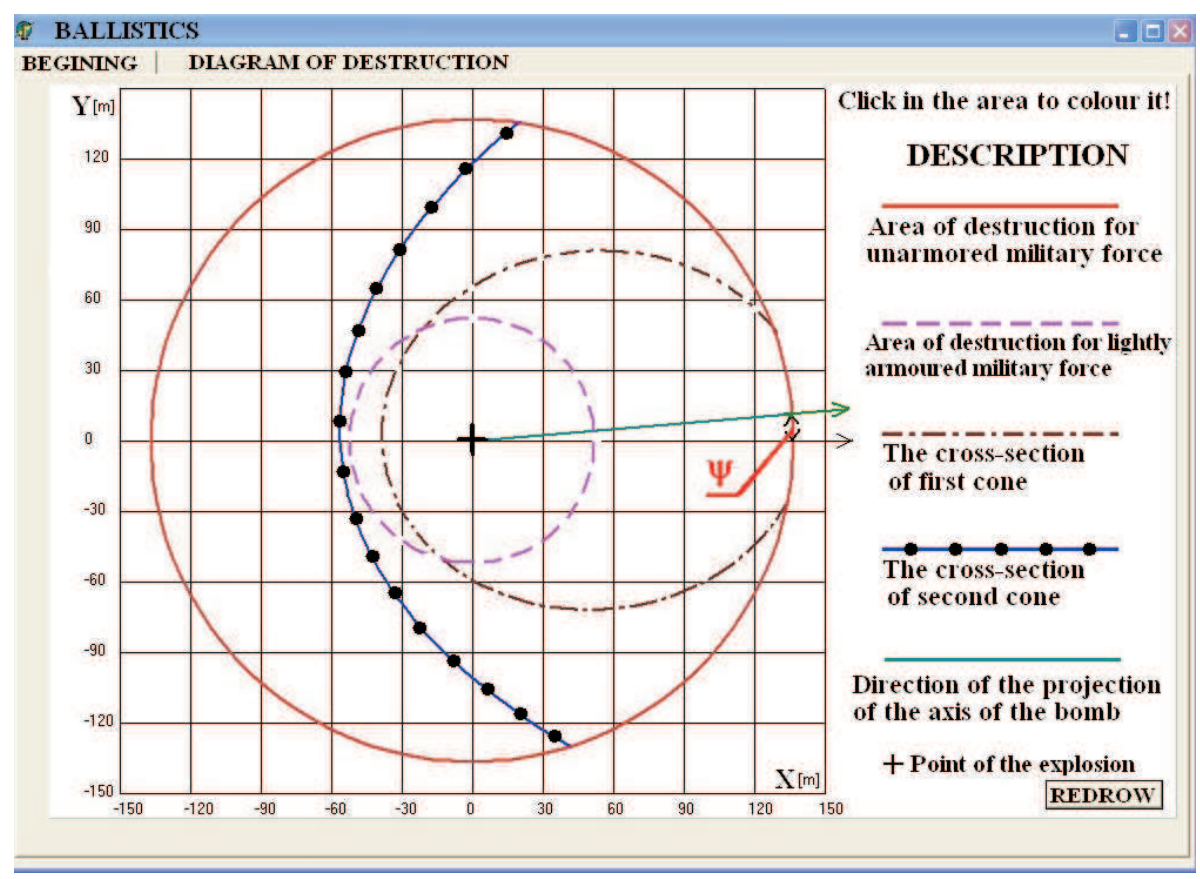

(b)

Fig. 4. (a) Input data about the sector of impact;

(b) areas of impact on the Earth's surface 


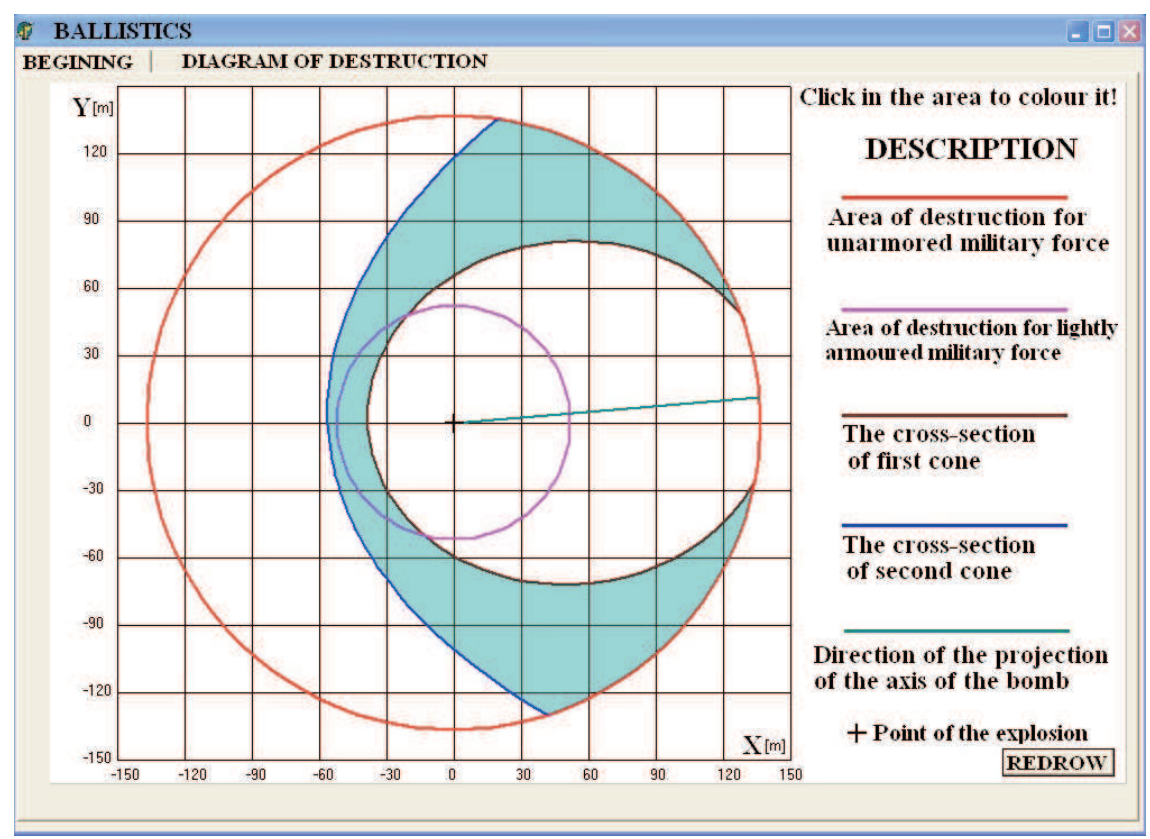

(a)

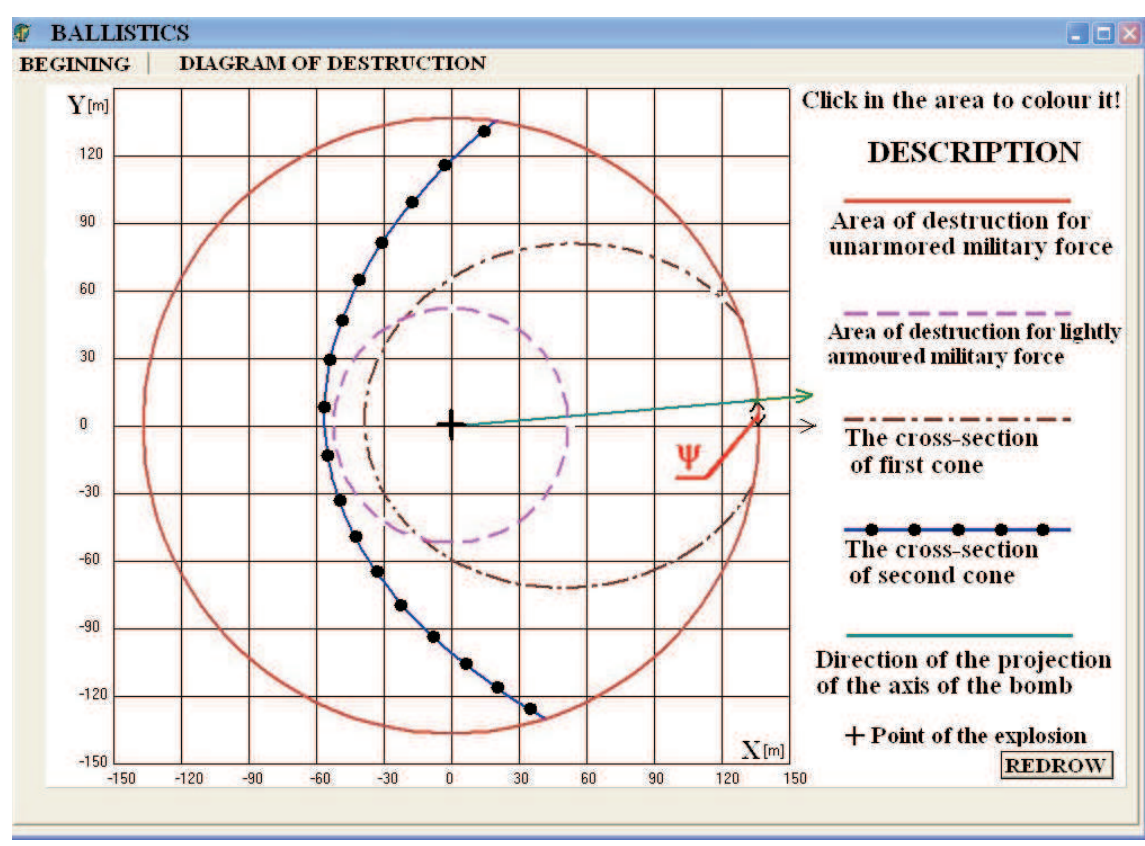

(b)

Fig. 5. (a) Area of destruction of UMF; (b) area of destruction of LAMF

(c) Инженерни науки, год. LVI, 2019, № 3

21

(C) Engineering Sciences, LVI, 2019, No. 3 
$D$ - distance between point of the explosion and plain position in the moment of explosion;

$t$ - flight duration.

The range tests of ammunition provide data about the strength of impact in a certain spatial sector [5]. It can be defined by the two angles $\gamma_{1}$ and $\gamma_{2}$, Fig. $4(a)$, of two cones with an axis of symmetry coinciding with the ammunition axis. The intersection of this spatial sector with the Earth's surface is obtained from the software and visualized as Fig. 4(b) shows.

Different ammunitions have different areas of destruction depending on the degree of protection of the military force. The red circles in Fig. 5(a) show these areas of destruction of unarmored and lightly armored military force. They together with the sections of the two cones outline the areas where one can expect impact after range tests. To improve the perspicuity of the results the software can color the whole area of these areas of destruction which is illustrated on next two figures. The area of destruction of unarmored military force (UMF) is shown in Fig. 5(a) and this one of Lightly Armored Military Force (LAMF) - in Fig. 5(b).

The angle $\Psi$ shows the rotation of the ammunition axis due to side wind. The software output is made available in digital form as ASCI files.

\section{CONCLUSION}

The authors hope that this study gives a useful product that could successfully solve a wide range of ballistics tasks. It could be especially useful in designing means for directing at bomb hits from airplanes as well as to evaluate the efficacy of different types of ammunition.

\section{ACKNOWLEDGEMENTS}

The authors would like to thank staff of "Dunarit" Rouse for the financial support of this work.

\section{REFERENCES}

[1] I. Zlatev, Theoretical Mechanics, Science and Art, Sofia (1965) 40-50 (in Bulgarian).

[2] M. D. Tinonov, G. I. Ignatsius and I. E. Smol'yaninov, Bombing, Gosudarstvennoe voennoe izdatel'stvo Narkomata oborony, SSSR, Moscow (1939) (in Russian).

(c) Инженерни науки, год. LVI, 2019, № 3

22

(C) Engineering Sciences, LVI, 2019, No. 3 
[3] International Organization for Standardization, Standard Atmosphere, ISO2533, 1975.

[4] Gr. Gyatr, A Mathematical Model of the 1976 U.S., Standard Atmosphere (2006), (2006-01-14).

[5] I. A. Balaganskij and L. A. MerzhievskiJ, Action of Means of Defeat and Ammunition, Izdatel'stvo NGTU, Novosibirsk (2004), ISBN 5-7782-0467-1, (in Russian).

МАТЕМАТИЧЕН МОДЕЛ НА ПОЛЕТА

НА БОЕПРИПАС, ИЗСТРЕЛЯН ОТ САМОЛЕТ, И НА ЗОНАТА МУ НА ПОРАЖЕНИЕ ПРИ ВЗРИВЯВАНЕ

ГЕОРГИ Евт. ГЕОРГИЕВ*, ВАлЕНТИН ДЖАМБОВ и САШо ПоПОВ

Институт по металознание, сгоргжения и технологии

с Центор по хидро- и аеродинамика „Акад. А. Балевски“, Бглгарска академия на науките,

бул. "Шипченски проход"№ 67, 1574 София, Бблгария, e-mails: g.georgiev@ims.bas.bg; valentin@ims.bas.bg; s.popov@ims.bas.bg

Резюме. Представен е математичен модел, решаващ задачата на балистиката за свободно падащо тяло в земната атмосфера. Той е базиран на законите на нютоновата механика, като се вземат предвид всички основни фактори, влияещи на траекторията на полета на тялото. Отчита се влиянието на променящата се плътност на земната атмосфера по височина, влиянието на страничния вятър, както и челното и страничното съпротивление. В случай, че тялото е боеприпас, моделът получава и визуализира зоната на поражение при неговото взривяване. Решенията на модела се получават посредством разработена за целта компютърна програма.

Ключови думи: балистика, математично моделиране, аеродинамика, зони на поражение, ефективност на боеприпаса.

Received June 19, 2019

(c) Инженерни науки, год. LVI, 2019, № 3 